Potential of faba bean lipase and lipoxygenase to promote formation of volatile lipid oxidation products in food models

\title{
Lampi, Anna-Maija
}

2020-05-01

Lampi , A-M , Yang , Z , Mustonen , O \& Piironen, V 2020 , ' Potential of faba bean lipase and lipoxygenase to promote formation of volatile lipid oxidation products in food models ', Food Chemistry , vol. 311 , 125982 . https://doi.org/10.1016/j.foodchem.2019.125982

http://hdl.handle.net/10138/323315

https://doi.org/10.1016/j.foodchem.2019.125982

cc_by_nc_nd

acceptedVersion

Downloaded from Helda, University of Helsinki institutional repository.

This is an electronic reprint of the original article.

This reprint may differ from the original in pagination and typographic detail.

Please cite the original version. 


\title{
Potential of faba bean lipase and lipoxygenase to promote formation of volatile lipid oxidation products in food models
}

\author{
Anna-Maija Lampi, Zhen Yang*, Otto Mustonen, Vieno Piironen \\ Department of Food and Nutrition, University of Helsinki, P.O. Box 66, FI-00014 Helsinki, Finland
}

\section{A R T I C L E I N F O}

\section{Keywords:}

Faba bean

Lipid-modifying enzymes

Lipase

Lipoxygenase

Lipid oxidation

Food models

Volatile lipid oxidation products

\begin{abstract}
A B S T R A C T
Faba bean can respond to the need for plant-based proteins for human consumption. The aim of this work was to study the role of lipid-modifying enzymes in faba bean in causing off-flavour compounds during processing. The faba bean exhibited high lipase and lipoxygenase (LOX) activities, with pH optima being 8.0 and 6.0, respectively. Faba bean LOX preferred free fatty acids (FFAs) over triacylglycerols as substrates, and together with other LOX pathway enzymes, it formed specific volatile products, as measured using headspace solid-phase microextraction-gas chromatography. During the preparation of the food models (i.e. the extracts and emulsions), enzymatic lipid oxidation occurred. The inclusion in the emulsions of rapeseed oil, especially of rapeseed oil FFAs, remarkably increased the amounts of volatile products. The largest quantities of products were formed in food models at $\mathrm{pH}$ 6.4, which is close to the $\mathrm{pH}$ optimum of LOX. Further studies on lipase in food models are needed.
\end{abstract}

\section{Introduction}

With the world's population growing rapidly, food security and environmental sustainability have become major challenges that necessitate enhanced use of plant proteins directly as human food (Calles, del Castello, Baratelli, Xipsiti, \& Navarro, 2019; Springmann et al., 2018). Cereals, legumes and oilseeds are the major sources of plant proteins whose physicochemical functionalities and nutritional properties are being extensively studied, but so far, they have been underutilized in food production (Day, 2013). The dry seeds of legumes (i.e. pulses) have earned more attention, especially after the Food and Agriculture Organisation of the United Nations (FAO) declared 2016 the 'International Year of Pulses' to emphasise the nutritional benefits of pulses as part of sustainable food production (Calles, del Castello, Baratelli, Xipsiti, \& Navarro, 2019). For example, pulses have become important ingredients and fortifying agents in bread-making, providing proteins and dietary fibre and complementing the amino acid profiles of wheat (Boukid, Zannini, Carini, \& Vittadini, 2019).

Faba bean (Vicia faba L.) is a staple crop worldwide that has a long cultivation tradition. In the cool northern hemisphere, it is the main grain legume cultivated. It belongs to the Fabaceae family. It has a high protein content, ranging from 24.3 to $32.2 \%$ of dry matter (Sparvoli, Bollini, \& Cominelli, 2015), which makes it a good source of plant protein. In addition, it contains $57-60 \%$ carbohydrates, of which
$37-51.5 \%$ is starch and $7.5-13.1 \%$ is dietary fibre, and a low lipid content of from 1.1 to $4 \%$ (Sparvoli et al., 2015). The Kontu faba bean cultivar grown in Finland contains an average of $13.7 \mathrm{mg} / \mathrm{g}$ of lipids calculated as the sum of fatty acids on a dry-matter basis (Lizarazo et al., 2015), and its proportions of linoleic and $\alpha$-linolenic acids are $54 \%$ and $4.8 \%$, respectively.

Increasing the use of plant-based proteins has a few challenges, including limited understanding of their functional properties, the presence of antinutrients and the formation of grainy or beany off-flavours (Day, 2013). Legumes are known to possess high activity of lipoxygenase (LOX) (linoleate: oxygen oxidoreductase, EC 1.13.11.12), which is the first enzyme to begin the lipid-degrading LOX pathway. LOX oxidises polyunsaturated fatty acids that have a 1,4-pentadiene structure and produces a variety of oxylipids, which are, for example, part of plant-defence reactions (Bleé, 1998). In foods, the main consequences of the LOX pathway are numerous volatile lipid oxidation products (Roland, Pouvreau, Curran, van de Valde, \& de Kok, 2017). First, LOX catalyses the formation of lipid hydroperoxides, which are cleaved into short-chain aldehydes, alcohols and hydrocarbons by enzymatic and non-enzymatic reactions (Gardner, 2003). The LOX pathway enzymes, including hydroperoxide lyase, can cause flavouractive compounds to form immediately (for example, the formation of fruity flavours when tomatoes are cut) (Jeleń \& Wąsowicz, 2012) or slowly, through reactions mediated by free radicals (for example,

\footnotetext{
* Corresponding author at: P.O. Box 66, Agnes Sjöbergin katu 2, FIN-00014 Helsinki, Finland.

E-mail address: zhen.yang@helsinki.fi (Z. Yang).
} 
during long-term storage of legume proteins; Hinchcliffe, McDaniel, Vaisey, \& Eskin, 1977). Great effort has been expended to solve the offflavour problem, especially in soybeans, and the most common means of controlling LOX activity is heat treatment (Roland et al., 2017). Novel approaches have been developed to enhance the effect of heat treatments, including the removal of off-flavour precursors in soybean protein isolates (Zhu \& Damodaran, 2018).

Among legumes, the faba bean is categorised as having a medium level of LOX activity (Chang \& McCurdy, 1985), which makes the LOX pathway and off-flavour formation a potential risk for faba bean foods. The products of the LOX pathway have been shown to occur in faba bean seeds (Oomah, Razafindrainibe, \& Drover, 2014) and in some food models subjected to storage (Gû́rbúz et al., 2018; Jiang et al., 2016). However, no studies have been conducted on the formation of LOX pathway products immediately during food preparation. Because LOXs have traditionally been considered as oxidising mainly free fatty acids (FFAs) (Mosblech, Feussner, \& Heilmann, 2009), the presence of FFAs is required. Thus, hydrolysis of acyl lipids to FFAs is considered a prerequisite for the LOX pathway. The faba bean is known to possess lipase (triacylglycerol acylhydrolase, EC 3.1.1.3) activity (Dundas, Henderson, \& Eskin, 1978; Yang, Piironen, \& Lampi, 2017), but no studies have shown its activity in food systems.

Our hypothesis was that as soon as faba bean flour is suspended in water, lipid-degrading enzymes are activated and lipid-derived volatile off-flavour products produced. Furthermore, reaction pathways are modified by the $\mathrm{pH}$ of the system and the presence of the lipids. Thus, the study's overall aim was to understand the role of lipid-modifying enzymes in faba bean in causing off-flavour compounds in foods during processing. Our approach was to characterise the $\mathrm{pH}$ optima and substrate specificity of faba bean lipase and LOX, and to study the substrate specificity of the faba bean LOX pathway in producing volatile lipid oxidation products. The final aim was to examine whether faba bean enzymes were able to promote the formation of volatile lipid oxidation products in selected food models under various $\mathrm{pH}$ conditions that occur in foods.

\section{Materials and methods}

\subsection{Samples, substrates and reagents}

The study used the Kontu faba bean cultivar harvested in 2011, 2015 and 2016. In addition, the Steinar oat cultivar harvested in 2014 was used as a reference when studying lipase activities. The faba beans were grown at the Viikki Experimental Farm (Lizarazo et al., 2015), and after harvest dried to a moisture content of $<14 \%$ and stored as presented earlier (Jiang et al., 2016). The oat seeds were provided by Boreal Plant Breeding Ltd. (Jokioinen, Finland). The seeds were milled using a ZM200 centrifugal mill (Retsch; Haan, Germany) to a particle size of $0.5 \mathrm{~mm}$, and the flours were stored at $-18{ }^{\circ} \mathrm{C}$ until use.

The enzyme activity experiments used oleic, linoleic and $\alpha$-linolenic acids, triolein and trilinolein (> 99\%; Nu-Check Prep, Elysian, MN) as lipid substrates, as well as rapeseed oil (Bunge; Raisio, Finland). To study lipase activity, $p$-nitrophenyl butyrate ( $p$-NPB) and $p$-nitrophenyl palmitate ( $p$-NPP) (Sigma-Aldrich; St. Louis, MO) were used as substrates. Rapeseed oil fatty acids were prepared by saponification. An aliquot of $250 \mathrm{mg}$ of rapeseed oil was saponified using $0.5 \mathrm{~mL}$ of saturated $\mathrm{KOH}$ in water and $8 \mathrm{~mL}$ of ethanol in a shaking water bath at $85{ }^{\circ} \mathrm{C}$ for $30 \mathrm{~min}$. Then, water was added to the reaction mixture and non-saponifiable lipids were extracted using a heptane:diethyl ether mixture (1:1). The FFAs were collected using $20 \mathrm{~mL}$ of the same solvent mixture from the aqueous phase after it was acidified to $\mathrm{pH} 4$ using $\mathrm{HCl}$. The FFAs from about $250 \mathrm{mg}$ of oil were dissolved in $20 \mathrm{~mL}$ of heptane. All other chemicals were of pro-analysis grade, and the solvents were of HPLC grade or equivalent.

\subsection{Methods to characterise lipase and LOX activities}

\subsubsection{Preparation of faba bean extracts}

To analyse enzyme activities, faba bean flours were mixed with water (Milli-Q; Millipore Corp., Bedford, MA), vortexed (4 × $10 \mathrm{~s}$ ), kept on ice for $60 \mathrm{~min}$ and then centrifuged at $10000 \mathrm{~g}$ for $10 \mathrm{~min}$. The supernatants were collected for analyses and named as extracts. The oat flour used as a reference for lipase analysis was processed similarly. The amounts of flours weighed were $2.0 \mathrm{~g}$ for the lipase analysis and $0.5 \mathrm{~g}$ for the LOX analysis, and the amounts of water added were $10 \mathrm{~mL}$ and $20 \mathrm{~mL}$, respectively. When needed, the extracts were diluted with water prior to the analyses.

\subsubsection{Measurement of lipase activity and substrate specificity}

To measure the optimal $\mathrm{pH}$ of faba bean lipase activity, a spectrophotometric method using $p$-NPB as the substrate was used (Yang et al., 2017). To compare the effect of the size of the acyl moiety on the lipase activity, $p$-NPP was also used as a substrate. Substrate solutions ( $2 \mathrm{mM})$ of $p$-NPB and $p$-NPP were freshly prepared from stock solutions in $50 \mathrm{mM} \mathrm{KH}_{2} \mathrm{PO}_{4}$ buffers (pHs 7.5 and 8.0) with $0.1 \%$ Triton X-100. The $p$-NPB substrate was prepared as presented earlier (Yang et al., 2017), and the $p$-NPP substrate was emulsified using an Ultra-Turrax ${ }^{\circledR}$ T25 homogeniser (IKA ${ }^{\circledR}$-Werke GmbH \& Co. KG, Staufen, Germany) for $5 \mathrm{~min}$ at $8000 \mathrm{rpm}$. In addition, to measure the effect of $\mathrm{pH}$ on lipase activity, $p$-NPB stock solution was diluted with $50 \mathrm{mM} \mathrm{KH}_{2} \mathrm{PO}_{4}$ buffers at pHs 4.5, 6.0 and 7.0.

To begin the hydrolysis, $3.6 \mathrm{~mL}$ of one of the substrate solutions was mixed with $0.4 \mathrm{~mL}$ of either faba bean or oat extract and incubated at $37^{\circ} \mathrm{C}$ for $30 \mathrm{~min}$. Prior to UV measurement at $\lambda=405 \mathrm{~nm}$, the reaction mixture was filtered through a $0.45-\mu \mathrm{m}$ Acrodisc syringe filter (SigmaAldrich; St. Louis, MO) when needed. Two types of controls were measured: reaction mixtures with inactivated enzymes to indicate the initial absorption, and substrate solutions without addition of an extract to detect natural decomposition of the substrates. Lipase activities were calculated by subtracting the $\Delta \mathrm{Abs}_{405} \mathrm{~nm}$ of the two controls from the reaction mixtures, and the results were calculated based on the release of $p$-nitrophenol using its molar absorptivity of $\varepsilon=16.05 \mathrm{mM}^{-1} \mathrm{~cm}^{-1}$. All measurements were made from triplicate extracts.

To further study the substrate specificity of faba bean lipases, solutions with $1 \%$ triolein, trilinolein and rapeseed oil emulsified with $1.35 \%$ Triton X-100 in $50 \mathrm{mM}$ Tris-buffer (pHs 7.5 and 8.0) were prepared. To begin the reaction, $1.5 \mathrm{~mL}$ of the substrate emulsion was mixed with $0.5 \mathrm{~mL}$ of either faba bean or oat extract and incubated in a shaking water bath at $37{ }^{\circ} \mathrm{C}$ for $90 \mathrm{~min}$. Thereafter, the enzymes were inactivated by adding $3 \mathrm{~mL}$ of ethanol and $100 \mu \mathrm{L}$ of $\mathrm{HCl}$, and the lipids were extracted twice using $10 \mathrm{~mL}$ of diethyl ether and finally dissolved in $10 \mathrm{~mL}$ of heptane. The degradation of the triacylglycerols (TAGs) was measured using normal-phase high-performance liquid chromatography with evaporative light scattering detection (NP-HPLC-ELSD), as presented earlier (Yang, Piironen, \& Lampi, 2019), and the loss of TAGs was reported as mg of substrate $\mathrm{min}^{-1} \mathrm{~g}^{-1}$ of flour. All measurements were made from duplicate extracts that had three replicate incubations.

\subsubsection{Measurement of LOX activity and product specificity}

LOX activity was measured using spectroscopy of the formation of hydroperoxides from linoleic acid (Yang et al., 2017). To measure LOX activity, $10 \mathrm{mM}$ linoleic acid solution in $1 \%$ Tween 20 in water was clarified with $1 \mathrm{M} \mathrm{NaOH}$ and used as the substrate. To $0.2 \mathrm{~mL}$ of the substrate solution, $2.6 \mathrm{~mL}$ of $0.1 \mathrm{M}$ potassium phosphate buffers at various $\mathrm{pHs}(4,5,6,6.8$ and 8.5$)$ and $0.2 \mathrm{~mL}$ of faba bean extract were added, and the mixture was incubated at $30{ }^{\circ} \mathrm{C}$ for $3 \mathrm{~min}$. The reaction was stopped by adding $3 \mathrm{~mL}$ of $0.1 \mathrm{M} \mathrm{NaOH}$. The formation of linoleic acid hydroperoxides $(\mathrm{mmol} /(\mathrm{g} \times \mathrm{min}))$ was measured using $\mathrm{UV}$ spectroscopy at $\lambda=234 \mathrm{~nm}$ and calculated using molar absorptivity of conjugated dienes of $\varepsilon=26000 \mathrm{M}^{-1} \mathrm{~cm}^{-1}$. Each measurement was made from two extracts that had three replicate incubations. 
To characterise the substrate specificity of faba bean LOX, the formation of volatile lipid oxidation products from linoleic and $\alpha$-linolenic acids and trilinolein were measured. These analyses were also meant to show the characteristic volatile product profiles of each lipid substrate. Each faba bean extract was incubated in $10 \mathrm{mM}$ substrate solution at $\mathrm{pH}$ 6. To begin the reaction, $400 \mu \mathrm{L}$ of the substrate solution and $400 \mu \mathrm{L}$ of the faba bean extract were added to $2.2 \mathrm{~mL}$ of the $0.1 \mathrm{M}$ potassium phosphate buffer ( $\mathrm{pH}$ 6.0) in a 20-mL amber SPME vial. The vial was closed using an aluminium cap with polytetrafluoroethylene (PTFE)/ silicone septum. After $10 \mathrm{~min}$ of incubation in a water bath at $30^{\circ} \mathrm{C}$, the enzymes were inactivated by adding $300 \mu \mathrm{L}$ of $1 \mathrm{M} \mathrm{HCl}$ through the cap septum. For the control samples, to indicate chemical lipid oxidation (i.e. autoxidation), $\mathrm{HCl}$ was added before the enzyme extract. Volatile lipid oxidation products were analysed using headspace, solid-phase microextraction gas chromatography mass spectrometry (HSSPME-GC-MS) using a divinylbenzene/Carboxen/polydimethylsiloxane (DVB/CAR/PDMS) 50/30- $\mu \mathrm{m}$ SPME fibre (SigmaAldrich) and SPB-624 column (30 m $\times 0.25 \mathrm{~mm}$ i.d., $1.4 \mu \mathrm{m}$; SigmaAldrich) and applying similar instrumental parameters as presented earlier (Yang et al., 2019). The only difference was that the stabilisation time of the sample in the injector was $10 \mathrm{~min}$.

The volatile compounds were identified by comparing their MS spectra with the database Wiley $7 \mathrm{~N}$ (Wiley Registry ${ }^{\mathrm{TM}}$ of Mass Spectral Data, 7th Edition, USA) and with the spectra from the standards, and by calculating the experimental linear retention index (LRI) for each compound as presented in Table S1. The amounts of volatile compounds were given as peak areas (counts $* \mathrm{~s} * 10^{6}$ ) of total ion counts $(\mathrm{m} / \mathrm{z} 30-500)$. The contents in the control samples were subtracted from their respective incubated samples. All measurements were made from duplicate extracts that had two replicate incubations and using one control from each extract.

In addition, to characterise the product specificity of faba bean LOX, the distribution of produced 9- and 13-hydroperoxides from linoleic acid was studied using HPLC. The faba bean extracts were incubated as presented above, using $1.12 \mathrm{mg}$ of linoleic acid as the substrate. After inactivating the enzymes, the hydroperoxides were collected by extracting twice with $10 \mathrm{~mL}$ of diethyl ether. The extracts were combined, evaporated to dryness and finally dissolved in $10 \mathrm{~mL}$ of heptane. The same normal phase (NP)-HPLC method as used to analyse the TAGs was used, except that UV detection $(\lambda=234 \mathrm{~nm})$ was used instead of ELSD. The linoleic acid hydroperoxides were identified using incubations with soybean LOX 1-B (lyophilised powder, $\geq 50000$ units/mg solid; SigmaAldrich, Gillingham, UK), which is known to mainly produce 13-hydroperoxides from linoleic acid (Gardner, 2003).

\subsection{Methods to analyse the potential of lipid-degrading enzymes in faba bean food models}

Finally, the potential of faba bean enzymes to promote the formation of volatile lipid oxidation products in food models was studied at three pHs, at which either the lipase or the LOX or both would have activity. The food models consisted of the extracts and the emulsions prepared from them. First, $3 \mathrm{~g}$ of faba bean flour was mixed with $12 \mathrm{~mL}$ of water ( $\mathrm{pH} 6.4$ ) or $0.1 \mathrm{M}$ potassium phosphate buffers (pHs 5.0 and 8.0) using a vortex mixer and allowed to stand for $10 \mathrm{~min}$ at room temperature. Then, the pHs were adjusted and the mixtures centrifuged at $10000 \mathrm{rpm}$ for $10 \mathrm{~min}$. The supernatants were collected and named as extracts. The emulsions were prepared by mixing the extracts with $3 \%$ and $5 \%$ of either rapeseed oil or rapeseed oil fatty acids using an Ultra-Turrax at $8000 \mathrm{rpm}$ for $2 \mathrm{~min}$. Immediately after preparing the extracts and the emulsions, aliquots of $3 \mathrm{~mL}$ of each of them were divided into 20 -mL SPME vials and placed in an autosampler set at $8{ }^{\circ} \mathrm{C}$ to be analysed using HS-SPME-GC-MS. Each measurement was made from a single extract that had three replicates.
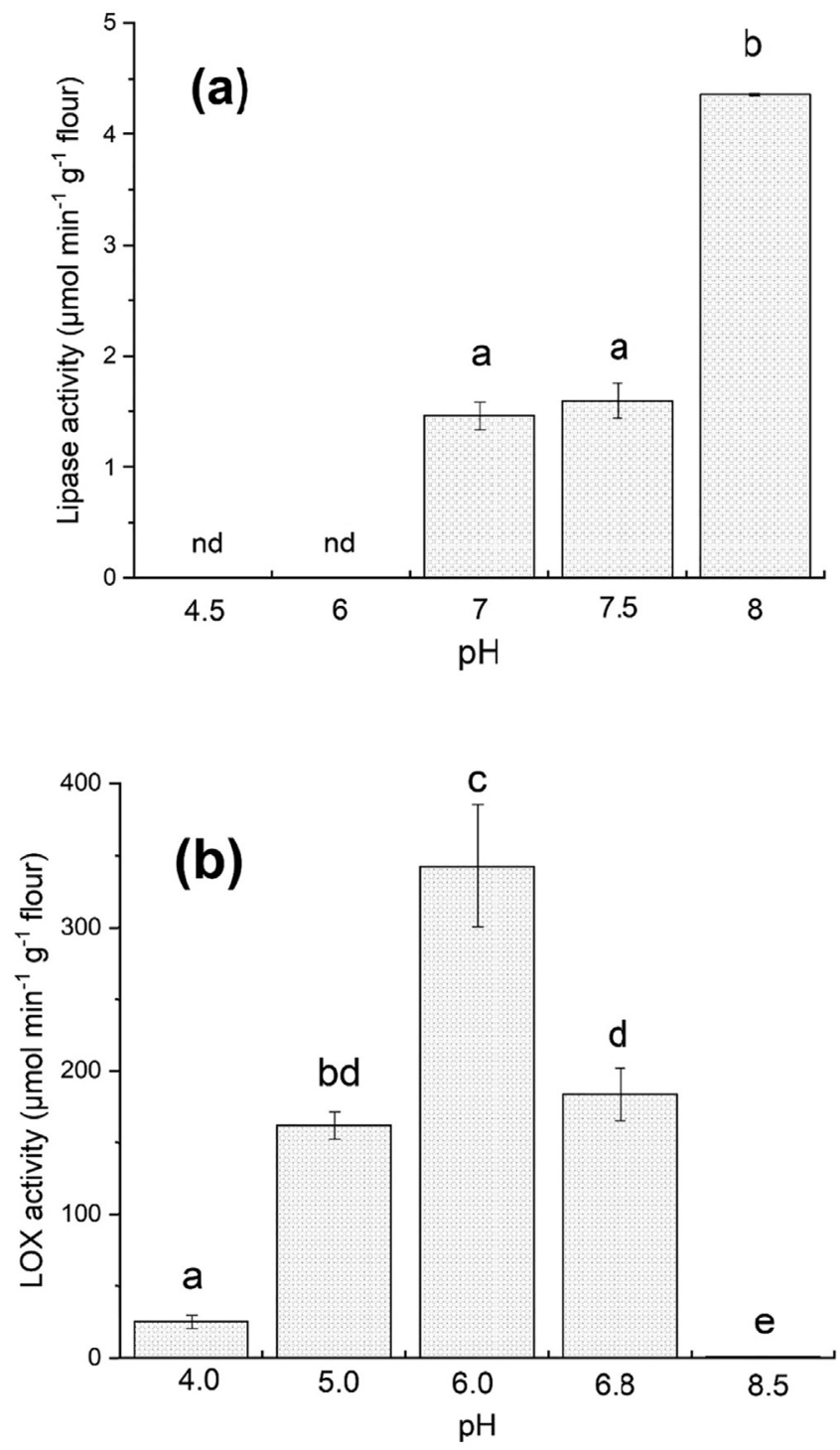

Fig. 1. Effect of faba bean extract pHs on the activity of (a) lipase using $p$-NPB as the substrate and (b) lipoxygenase (LOX) using linoleic acid as the substrate. Different letters (a-e) above each column indicate significant differences as estimated by Tukey's test $(p<0.05)$.

\subsection{Statistical analysis}

All results were expressed as mean values \pm standard deviations. Statistical analysis was performed by one-way analysis of variance (ANOVA) followed by Tukey's test using SPSS version 22 (IBM SPSS Statistics, USA). A value of $p<0.05$ was considered statistically significant. Figures were drawn using OriginPro 8.6 (OriginLab Corporation, Northampton, MA).

\section{Results and discussion}

\subsection{Characterisation of faba bean lipase and LOX}

The Faba bean lipase (Kontu cultivar, from 2016) and LOX (Kontu, from 2011) had different $\mathrm{pH}$ optima (Fig. 1). The lipase showed greater activity at $\mathrm{pH} 8.0$ than at lower $\mathrm{pH}$ values, and no activity was present at $\mathrm{pH}$ 6. Earlier, faba bean lipase was shown to have its highest activity under alkaline $\mathrm{pH}$ of 8.5 (Dundas et al., 1978; Henderson, Shambrock, \& Eskin, 1981). LOX had the highest activity at pH 6.0, and the activity decreased by half at pHs 5 and 6.8. This is in line with the results of Al- 

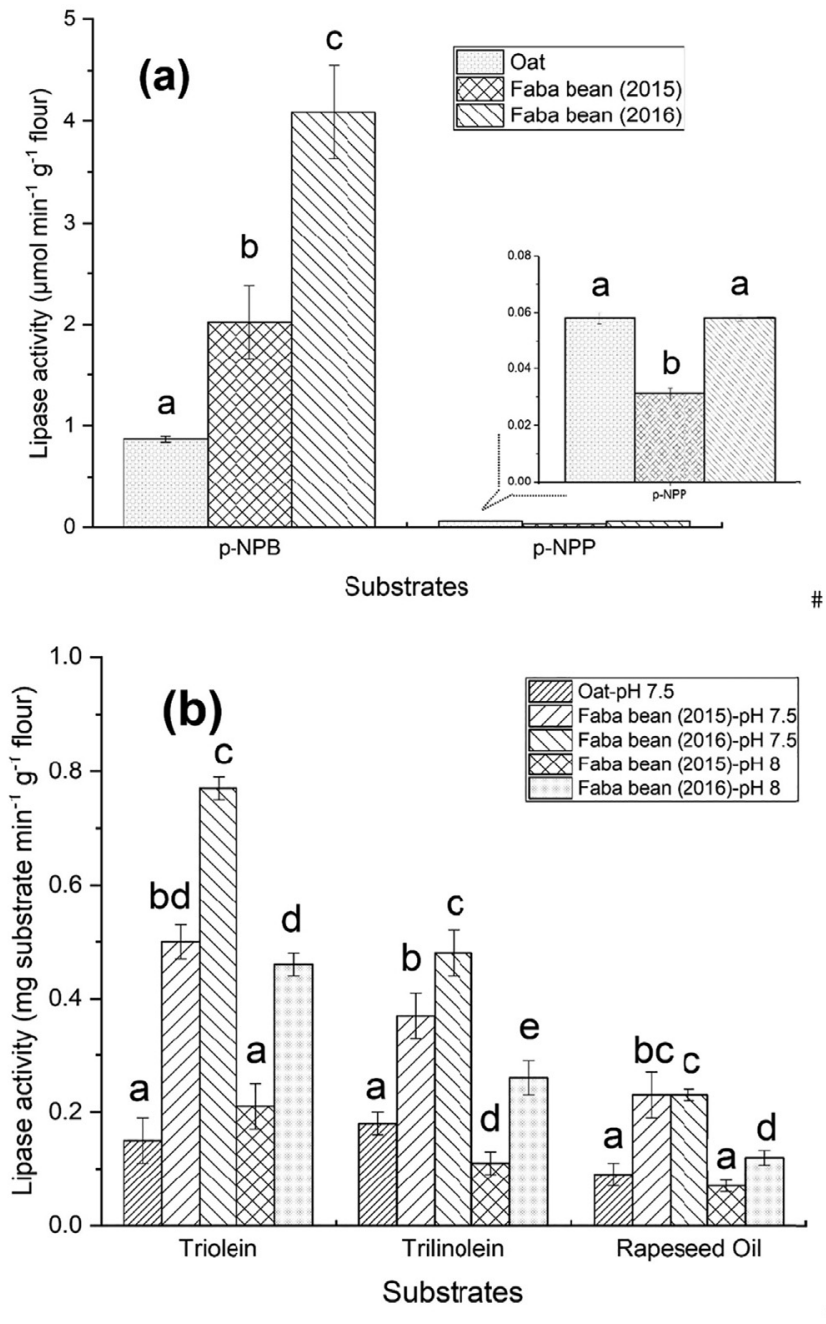

Fig. 2. Substrate specificity of faba bean lipase using (a) p-nitrophenyl butyrate ( $p$-NPB) and $p$-nitrophenyl palmitate ( $p$-NPP) at $\mathrm{pH} 8$ and (b) triolein, trilinolein and rapeseed oil at pHs 7.5 and $8(n=6$, mean \pm standard deviation). Oat lipase was included to compare it with faba bean lipase. Different letters (a-e) above each column within each substrate indicate significant differences as estimated by Tukey's test $(p<0.05)$.

Obaidy and Siddiqi (1981) and of Clemente, Olías, and Olías (2000), the latter of whom further stated that the $\mathrm{pH}$ optimum of faba bean LOX was about $\mathrm{pH} 5.8$ and that activity was reduced to $<60 \%$ at both $\mathrm{pH}$ 5.0 and $\mathrm{pH}$ 7.0. Our results showed that although the faba bean possesses lipase and LOX activities, it is apparent that the enzymes prefer to be active at different pHs.

Because using $p$-NPB may detect nonspecific hydrolyses when measuring lipase activity, results obtained with $p$-NPB have been criticised (Gilham \& Lehner, 2005). Thus in the present study, lipase activity was also measured using $p$-NPP and selected TAGs. In both faba bean and oat seeds, the activity observed was much less when $p$-NPP rather than $p$-NPB was used as a substrate (Fig. 2a). With $p$-NPB as the substrate, greater lipase activity was observed in the faba bean seeds from the cultivation years 2015 and 2016 than in the reference oat seeds (year 2014). With $p$-NPP as the substrate, the activity of the faba bean extracts was the same (year 2016) or even less (year 2015) than that of the oat extract (Fig. 2a). All measurements showed that the activity in faba beans seeds from 2016 was clearly greater than that from 2015, which could be due to their original activities or to differences in storage. Interestingly, lipase activity as measured using the loss of TAG substrates again showed that the extract from faba bean seeds from 2016 had the highest activity, followed by that of faba bean seeds
Table 1

Enzymatic formation of volatile lipid oxidation products in faba bean extracts using linoleic acid, $\alpha$-linolenic acid and trilinolein as substrates $(n=4)$.

\begin{tabular}{|c|c|c|c|}
\hline \multirow[t]{2}{*}{ Compound } & \multicolumn{3}{|c|}{$\begin{array}{l}\text { Amounts of volatile compounds (peak areas, } \times 10^{6} \text { ) with } \\
\text { different substrates }\end{array}$} \\
\hline & Linoleic acid & $\alpha$-linolenic acid & Trilinolein \\
\hline 1-penten-3-one & nd & $1.68 \pm 0.26$ & nd \\
\hline (E)-2-pentenal & nd & $1.23 \pm 0.05$ & nd \\
\hline hexanal & $94.7 \pm 6.3$ & $2.59 \pm 0.82$ & $7.70 \pm 2.56$ \\
\hline 2-heptanone & $3.94 \pm 0.33$ & nd & nd \\
\hline (E)-2-hexenal & nd & $5.38 \pm 0.43$ & nd \\
\hline heptanal & $2.36 \pm 0.45$ & nd & nd \\
\hline 2-pentylfuran & $18.8 \pm 1.5$ & nd & nd \\
\hline (E)-2-heptenal & $3.41 \pm 0.56$ & nd & nd \\
\hline 1-octen-3-ol & $3.73 \pm 0.61$ & nd & nd \\
\hline $\begin{array}{l}\text { sum of }(E, Z)-\text { and } \\
(E, E)-2,4- \\
\text { heptadienal }\end{array}$ & nd & $20.6 \pm 4.6$ & nd \\
\hline (E)-2-octenal & $16.2 \pm 2.1$ & nd & nd \\
\hline $\begin{array}{l}(E, E)-3,5 \text {-octadien-2- } \\
\quad \text { one }\end{array}$ & nd & $4.94 \pm 3.78$ & nd \\
\hline 2-nonanone & nd & $1.0 \pm 0.80$ & nd \\
\hline$(E, E)-2,4$-nonadienal & $6.28 \pm 0.59$ & nd & nd \\
\hline $\begin{array}{l}(E, E, E)-2,4,6- \\
\text { nonatrienal }\end{array}$ & nd & $5.29 \pm 2.12$ & nd \\
\hline $\begin{array}{c}\text { sum of }(E, Z)-\text { and } \\
(E, E)-2,4- \\
\text { decadienal }\end{array}$ & $5.45 \pm 0.95$ & nd & nd \\
\hline
\end{tabular}

nd: not detected.

from 2015, while the lowest activity was measured in the extract from oat seeds (Fig. 2b). The same trend was observed with all three TAG substrates. The lipases seemed to hydrolyse homogenous triolein and trilinolein better than complex rapeseed oil TAGs, indicating that the TAG structure may affect the interaction of the substrate with the enzyme. Kinetic studies on faba bean lipase have shown that it prefers the glycerides of short-chain fatty acids over the glycerides of long-chain fatty acids (Dundas et al., 1978). Finally, lipase activity with TAGs was higher at $\mathrm{pH} 7.5$ than at $\mathrm{pH} 8$, which is the opposite of what was observed with $p$-NPB and which could be due to the fact that $p$-NPB is a non-specific substrate for many hydrolyses. The results of the present study clearly show that endogenous lipase should be carefully controlled when producing faba bean products, as the potential of faba bean lipase is even greater than that of oat lipase, which is known for its high lipase activity.

\subsection{Hydroperoxides and volatile lipid oxidation products from faba bean LOX pathway}

Faba bean LOX was able to oxidise both linoleic and $\alpha$-linolenic acids, whereas trilinolein was a poor substrate for it (Table 1), which means that faba bean LOX preferred FFAs over acyl esters as substrates, as do most LOXs (e.g. Schaich, Shahidi, Zhong, \& Eskin, 2013; Roland et al., 2017). Apparently, under the incubation conditions used, faba bean lipase was unable to hydrolyse trilinolein into linoleic acid, which could be due to the small amount of faba bean extract, too low pH (6) and a relatively short 10-min incubation. Studies that used linoleic acid as the substrate found that faba bean LOX produced more 9-hydroperoxides than 13-hydroperoxides as primary products. In the present study, the proportion of 9-hydroperoxides was $59.9 \% \pm 0.2 \%$ and $61.2 \% \pm 0.6 \%$ in extracts from faba beans cultivated in 2015 and 2016, respectively $(n=4)$. This is in line with the results of Clemente et al. (2000), who found a similar ratio of hydroperoxides when using faba bean LOX isoenzyme 1 . The hydroperoxide ratio was expected to be reflected in the proportions of the volatile lipid oxidation products.

In the LOX pathway, lipid hydroperoxides are subjected to hydroperoxide lyase and further degrading enzymes to produce volatile lipid 
Table 2

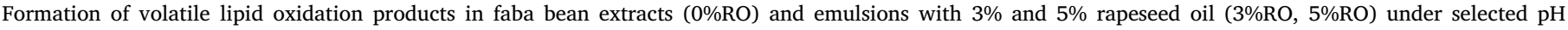
conditions.*

\begin{tabular}{|c|c|c|c|c|c|c|c|c|c|}
\hline \multirow[t]{2}{*}{ Compound } & \multicolumn{3}{|c|}{ pH 5 (counts * s * $10^{6}$ ) } & \multicolumn{3}{|c|}{ pH 6.4 (counts * $\mathrm{s} * 10^{6}$ ) } & \multicolumn{3}{|c|}{$\mathrm{pH} 8$ (counts * $\mathrm{s} * 10^{6}$ ) } \\
\hline & $0 \% \mathrm{RO}$ & $3 \% \mathrm{RO}$ & $5 \%$ RO & $0 \%$ RO & $3 \% \mathrm{RO}$ & $5 \%$ RO & $0 \%$ RO & $3 \% \mathrm{RO}$ & $5 \%$ RO \\
\hline \multicolumn{10}{|l|}{ Faba bean (Kontu 2016) } \\
\hline 1-penten-3-one & nd & $1.4 \pm 0.3$ & $2.9 \pm 0.6$ & nd & $0.2 \pm 0.09$ & $0.3 \pm 0.07$ & nd & nd & nd \\
\hline (E)-2-pentenal & nd & $0.9 \pm 0.2$ & $2.4 \pm 0.4$ & nd & $4.6 \pm 0.6$ & $6.3 \pm 0.6$ & nd & $0.4 \pm 0.1$ & $0.2 \pm 0.0$ \\
\hline hexanal & $13.0 \pm 0.2$ & $12.2 \pm 2.6$ & $12.4 \pm 0.8$ & $7.4 \pm 0.9$ & $17.2 \pm 1.4$ & $21.5 \pm 1.6$ & $2.4 \pm 0.5$ & $3.5 \pm 0.2$ & $2.2 \pm 0.3$ \\
\hline (E)-2-hexenal & $0.8 \pm 0.2$ & $0.6 \pm 0.1$ & $1.0 \pm 0.1$ & nd & $0.6 \pm 0.1$ & $0.6 \pm 0.1$ & nd & nd & nd \\
\hline 1-hexanol & $0.6 \pm 0.1$ & nd & $0.3 \pm 0.1$ & $4.5 \pm 1$ & $7.1 \pm 1.2$ & $7.6 \pm 2.2$ & $0.1 \pm 0.0$ & $0.2 \pm 0.0$ & nd \\
\hline heptanal & nd & $0.5 \pm 0.2$ & $0.5 \pm 0.1$ & nd & $2.5 \pm 0.3$ & $4.7 \pm 1.2$ & nd & nd & nd \\
\hline 2-pentylfuran & $1.4 \pm 0.1$ & nd & $0.1 \pm 0.0$ & $4.2 \pm 1.1$ & $1.6 \pm 0.1$ & $2.3 \pm 0.2$ & $0.2 \pm 0.0$ & $0.1 \pm 0.0$ & $0.1 \pm 0.0$ \\
\hline (E)-2-heptenal & $0.2 \pm 0.1$ & $0.7 \pm 0.1$ & $0.9 \pm 0.1$ & nd & $2.7 \pm 0.2$ & $4.5 \pm 0.2$ & nd & nd & nd \\
\hline 1-octen-3-ol & $1.6 \pm 0.7$ & $0.2 \pm 0.03$ & $0.2 \pm 0.0$ & $3.1 \pm 1.4$ & $3.2 \pm 0.6$ & $3.4 \pm 0.4$ & $0.5 \pm 0.1$ & $0.6 \pm 0.1$ & $0.3 \pm 0.1$ \\
\hline octanal & nd & $0.4 \pm 0.1$ & $0.4 \pm 0.1$ & $0.3 \pm 0.1$ & $0.5 \pm 0.1$ & $0.8 \pm 0.1$ & nd & nd & nd \\
\hline sum of $(E, Z)$ - and $(E, E)-2,4$-heptadienal & nd & nd & $0.3 \pm 0.0$ & nd & $1.4 \pm 0.4$ & $2.8 \pm 0.3$ & nd & nd & nd \\
\hline (E)-2-octenal & nd & $0.2 \pm 0.0$ & $0.3 \pm 0.0$ & nd & $1.6 \pm 0.3$ & $2.0 \pm 0.1$ & nd & nd & nd \\
\hline nonanal & $0.2 \pm 0.1$ & $0.8 \pm 0.0$ & $0.7 \pm 0.1$ & $2.0 \pm 0.8$ & $3.9 \pm 0.5$ & $4.1 \pm 0.4$ & $0.3 \pm 0.1$ & $1.0 \pm 0.0$ & $0.4 \pm 0.1$ \\
\hline$(E, E)$-3,5-octadien-2-one & nd & nd & nd & nd & nd & nd & nd & nd & nd \\
\hline octanoic acid & nd & nd & nd & $1.7 \pm 0.5$ & $0.8 \pm 0.2$ & $1.4 \pm 0.3$ & nd & nd & nd \\
\hline \multicolumn{10}{|l|}{ Faba bean (Kontu 2015) } \\
\hline 1-penten-3-one & nd & $2.1 \pm 0.7$ & $4.1 \pm 1.8$ & nd & $1.3 \pm 0.3$ & $1.4 \pm 0.7$ & nd & $1.1 \pm 0.0$ & $1.0 \pm 0.4$ \\
\hline (E)-2-pentenal & nd & $2.5 \pm 0.8$ & $3.8 \pm 1.0$ & nd & $3.5 \pm 0.6$ & $6.1 \pm 0.7$ & nd & $0.2 \pm 0.0$ & $0.2 \pm 0.0$ \\
\hline hexanal & $10.7 \pm 0.4$ & $14.4 \pm 1.2$ & $10.9 \pm 3.7$ & $6.9 \pm 0.8$ & $15.5 \pm 3.5$ & $22.2 \pm 4.5$ & $2.5 \pm 0.5$ & $3.1 \pm 0.2$ & $2.4 \pm 0.1$ \\
\hline (E)-2-hexenal & $0.4 \pm 0.1$ & $1.0 \pm 0.3$ & $0.8 \pm 0.2$ & nd & $1.1 \pm 0.1$ & $2.3 \pm 0.4$ & nd & nd & nd \\
\hline 1-hexanol & nd & $0.4 \pm 0.2$ & $0.1 \pm 0.0$ & $5.6 \pm 0.4$ & $6.9 \pm 2.4$ & $7.6 \pm 2.0$ & nd & $0.3 \pm 0.1$ & $0.1 \pm 0.0$ \\
\hline heptanal & nd & $1.0 \pm 0.4$ & $0.9 \pm 0.3$ & nd & $2.2 \pm 0.8$ & $3.8 \pm 0.9$ & nd & nd & nd \\
\hline 2-pentylfuran & $0.5 \pm 0.1$ & $0.1 \pm 0.06$ & $0.1 \pm 0.0$ & $3.0 \pm 0.2$ & $0.6 \pm 0.2$ & $0.7 \pm 0.2$ & $0.1 \pm 0.0$ & $0.1 \pm 0.0$ & $0.03 \pm 0.01$ \\
\hline (E)-2-heptenal & nd & $1.7 \pm 0.5$ & $1.2 \pm 0.2$ & nd & $1.7 \pm 0.5$ & $3.0 \pm 0.5$ & nd & nd & nd \\
\hline 1-octen-3-ol & $2.0 \pm 0.6$ & $0.7 \pm 0.1$ & $0.8 \pm 0.1$ & $2.3 \pm 0.0$ & $2.3 \pm 0.8$ & $2.8 \pm 0.6$ & $0.4 \pm 0.1$ & $0.5 \pm 0.1$ & $0.2 \pm 0.06$ \\
\hline octanal & $0.04 \pm 0.01$ & $0.9 \pm 0.3$ & $0.5 \pm 0.1$ & nd & $0.4 \pm 0.1$ & $0.7 \pm 0.1$ & nd & nd & nd \\
\hline sum of $(E, Z)$ - and $(E, E)-2,4$-heptadienal & nd & $0.7 \pm 0.2$ & $0.5 \pm 0.1$ & nd & $0.8 \pm 0.3$ & $2.2 \pm 0.4$ & nd & nd & nd \\
\hline (E)-2-octenal & nd & $0.7 \pm 0.3$ & $0.3 \pm 0.1$ & nd & $1.1 \pm 0.2$ & $1.6 \pm 0.2$ & nd & nd & nd \\
\hline nonanal & $0.3 \pm 0.1$ & $1.7 \pm 0.5$ & $1.0 \pm 0.4$ & nd & $2.9 \pm 0.6$ & $3.4 \pm 0.3$ & $0.3 \pm 0.1$ & $0.5 \pm 0.1$ & $0.2 \pm 0.05$ \\
\hline$(E, E)$-3,5-octadien-2-one & nd & nd & nd & nd & nd & nd & nd & nd & nd \\
\hline octanoic acid & nd & nd & nd & $0.2 \pm 0.0$ & $0.2 \pm 0.1$ & $0.3 \pm 0.1$ & nd & nd & nd \\
\hline
\end{tabular}

* Faba bean extracts were prepared from the Kontu cultivar from two harvesting years (2015, 2016). (3 replicate measurements; nd: not detected.)

oxidation products. In the faba bean extracts, various profiles of volatile compounds were produced from the linoleic and $\alpha$-linolenic acids (Table 1). The products were expected to be formed by enzymatic reactions, due to the short 10-min incubation. Furthermore, the results of the control samples that had no enzyme activity showed only minor amounts of volatile compounds (data not shown), indicating insignificant autoxidation.

The volatile compounds presented in Tables 1-3 were identified as shown in Table S1. The calculated LRI values for the volatiles were in line with those presented by Paradiso, Summo, Pasqualone, and Caponio (2009), while the mass spectra were in line with those obtained from standards and/or the Wiley $7 \mathrm{~N}$ database. For linoleic acid, hexanal was the dominant product, followed by 2-pentylfuran and $(E)$ 2-octenal. The profile does not reflect the proportions of the hydroperoxides, as hexanal is the primary scission product of 13-hydroperoxide (Belitz, Grosch, \& Schieberle, 2004; Jeleń \& Wąsowicz, 2012), which contributed to only $40 \%$ of the hydroperoxides. Only a small amount of the primary scission product of the major 9-hydroperoxide $(60 \%)$, namely 2,4-decadienal (including both $2 E, 4 Z$ - and $2 E, 4 E$ - isomers), was observed, whereas the further reaction product of the scission product nonenyl radical, namely 2-pentylfuran, was shown to be present in high amounts. It has been suggested that the specificity of the hydroperoxide degrading enzyme hydroperoxide lyase has greater influence on the aroma profiles than on LOX specificity (Sanz \& Pérez, 2010), which may explain the dominance of the products of linoleic acid 13-hydroperoxides. To our knowledge, no studies have been conducted on hydroperoxide lyase or other further LOX pathway enzymes in faba bean. The third major product, $(E)$-2-octenal, has also been measured in autoxidised linoleic acid (Belitz et al., 2004). Sanz and Pérez (2010) found that the initially formed 3-cis-aldehydes were rapidly enzymatically converted to 2-trans-aldehydes, which could explain the presence of $(E)$-2-hexenal, $(E)$-2-heptenal and $(E)$-2-octenal. In the present study, the only alcohol measured from the enzymatically oxidised linoleic acid was 1-octen-3-ol, which has been associated with enzymatic reactions (Sanz \& Pérez, 2010; Jeleń \& Wąsowicz, 2012). However, no 1-hexanol produced by alcohol dehydrogenase was detected. When trilinolein was used as the substrate, only hexanal was formed, and its amount was only $8 \%$ of that of the linoleic acid (Table 1).

With $\alpha$-linolenic acid as the substrate, 2,4-heptadienal (including both $2 E, 4 Z$ - and $2 E, 4 E$ - isomers) was the major product, and (E)-2hexenal, $(E, E, E)-2,4,6$-nonatrienal and $(E, E)$-3,5-octadien-2-one were the other characteristic products. All these products are typical for autoxidised n-3 polyunsaturated fatty acids (Belitz et al., 2004) and have been shown to be built up in enzymatic reactions (Jeleń \& Wąsowicz, 2012; Sanz \& Pérez, 2010). The major product, 2,4-heptadienal, is the primary scission product of 12-hydroperoxide, although faba bean LOX is expected to produce mainly 9- and 13-hydroperoxides (Gardner, 2003). Reactions catalysed by LOX, hydroperoxide lyase and isomerase have been found to form $(E)$-2-hexenal from the 13-hydroperoxide of $\alpha$-linolenic acid (Baysal \& Demirdöven, 2007; Bleé, 1998).

\subsection{Enzymatic formation of volatile lipid oxidation products in faba bean food models}

Finally, the potential of lipid-modifying enzymes in faba bean to rapidly produce volatile lipid oxidation products was studied in one extract and four emulsions produced at three pHs. In the emulsions, the type and amount of added lipid was altered. The model at pH 5.0 represents fermented foods, whereas the models at $\mathrm{pH} 6.4$ and $\mathrm{pH} 8$ 
Table 3

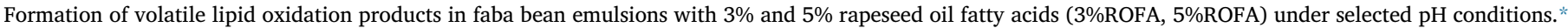

\begin{tabular}{|c|c|c|c|c|c|c|}
\hline \multirow[t]{2}{*}{ Compound } & \multicolumn{2}{|c|}{ pH 5 (counts * s * $10^{6}$ ) } & \multicolumn{2}{|c|}{ pH 6.4 (counts * $\mathrm{s} * 10^{6}$ ) } & \multicolumn{2}{|c|}{$\mathrm{pH} 8$ (counts * $\mathrm{s} * 10^{6}$ ) } \\
\hline & $3 \%$ ROFA & 5\%ROFA & $3 \%$ ROFA & 5\%ROFA & 3\%ROFA & 5\%ROFA \\
\hline \multicolumn{7}{|l|}{ Faba bean (Kontu 2016) } \\
\hline 1-penten-3-one & $5.5 \pm 0.6$ & $10.4 \pm 2.2$ & $5.4 \pm 0.1$ & $7.2 \pm 1.1$ & $0.5 \pm 0.1$ & $1.5 \pm 0.5$ \\
\hline (E)-2-pentenal & $4.7 \pm 0.7$ & $7.9 \pm 0.7$ & $7.5 \pm 0.7$ & $10.1 \pm 0.8$ & $4.4 \pm 1.3$ & $7.3 \pm 1.8$ \\
\hline hexanal & $19.4 \pm 2.8$ & $20.2 \pm 3.1$ & $33.0 \pm 3.9$ & $29.0 \pm 2.7$ & $11.7 \pm 2.8$ & $12.0 \pm 3.5$ \\
\hline (E)-2-hexenal & $2.4 \pm 0.6$ & $3.2 \pm 0.1$ & $13.0 \pm 3.7$ & $11.2 \pm 1.1$ & $4.5 \pm 0.8$ & $3.9 \pm 0.7$ \\
\hline 1-hexanol & nd & nd & $4.3 \pm 1.8$ & $1.6 \pm 0.3$ & $0.2 \pm 0.1$ & $0.2 \pm 0.0$ \\
\hline heptanal & $2.4 \pm 0.3$ & $3.3 \pm 0.4$ & $3.0 \pm 1.0$ & $4.1 \pm 0.6$ & $1.6 \pm 0.9$ & $2.7 \pm 0.8$ \\
\hline 2-pentylfuran & $0.8 \pm 0.3$ & $0.7 \pm 0.1$ & $7.9 \pm 0.3$ & $5.4 \pm 0.5$ & $4.2 \pm 1.1$ & $4.5 \pm 0.6$ \\
\hline (E)-2-heptenal & $7.9 \pm 1.4$ & $9.5 \pm 0.2$ & $11.1 \pm 3.5$ & $12.9 \pm 1.0$ & $1.1 \pm 0.4$ & $2.4 \pm 0.5$ \\
\hline 1-octen-3-ol & $1.8 \pm 0.2$ & $2.5 \pm 0.3$ & $10.1 \pm 4.9$ & $9.3 \pm 0.8$ & $2.3 \pm 0.6$ & $2.8 \pm 0.4$ \\
\hline octanal & $1.5 \pm 0.2$ & $1.7 \pm 0.1$ & $4.1 \pm 1.9$ & $2.5 \pm 0.2$ & nd & nd \\
\hline sum of $(E, Z)$ - and $(E, E)-2,4$-heptadienal & $13.0 \pm 2.8$ & $15.0 \pm 0.8$ & $8.0 \pm 2.3$ & $15.6 \pm 1.3$ & $0.8 \pm 0.2$ & $3.2 \pm 0.5$ \\
\hline (E)-2-octenal & $4.5 \pm 1.2$ & $5.2 \pm 0.5$ & $1.6 \pm 0.3$ & $2.0 \pm 0.1$ & $1.0 \pm 0.5$ & $1.9 \pm 0.5$ \\
\hline nonanal & $3.6 \pm 0.5$ & $3.1 \pm 0.2$ & $10.0 \pm 2.6$ & $6.4 \pm 0.3$ & $2.8 \pm 0.7$ & $2.7 \pm 0.3$ \\
\hline$(E, E)-3,5$-octadien-2-one & $2.0 \pm 0.7$ & $1.7 \pm 0.3$ & $2.4 \pm 0.1$ & $2.5 \pm 0.2$ & $0.4 \pm 0.2$ & $1.0 \pm 0.3$ \\
\hline octanoic acid & $0.8 \pm 0.4$ & $0.7 \pm 0.1$ & $2.4 \pm 1.0$ & $2.3 \pm 0.1$ & $0.7 \pm 0.0$ & $0.9 \pm 0.1$ \\
\hline \multicolumn{7}{|l|}{ Faba Bean (Kontu 2015) } \\
\hline 1-penten-3-one & $7.7 \pm 1.0$ & $13.3 \pm 3.2$ & $5.2 \pm 0.4$ & $8.5 \pm 1.2$ & $0.7 \pm 0.3$ & $0.4 \pm 0.2$ \\
\hline (E)-2-pentenal & $5.7 \pm 1.0$ & $12.6 \pm 1.8$ & $6.4 \pm 0.6$ & $9.3 \pm 1.7$ & $4.6 \pm 1.2$ & $5.1 \pm 0.3$ \\
\hline hexanal & $22.4 \pm 0.1$ & $20.0 \pm 2.7$ & $28.1 \pm 4.3$ & $26.4 \pm 2.3$ & $7.0 \pm 1.8$ & $7.2 \pm 1.3$ \\
\hline (E)-2-hexenal & $4.0 \pm 1.0$ & $7.3 \pm 1.2$ & $8.1 \pm 0.4$ & $8.3 \pm 0.5$ & $5.4 \pm 1.5$ & $2.9 \pm 0.7$ \\
\hline 1-hexanol & nd & nd & $2.0 \pm 0.2$ & $1.8 \pm 0.0$ & $1.1 \pm 0.3$ & $0.3 \pm 0.1$ \\
\hline heptanal & $4.3 \pm 1.1$ & $8.4 \pm 2.3$ & $3.1 \pm 0.4$ & $3.0 \pm 0.7$ & $1.8 \pm 0.7$ & $3.0 \pm 1.2$ \\
\hline 2-pentylfuran & $1.0 \pm 0.2$ & $1.6 \pm 0.3$ & $5.4 \pm 0.6$ & $3.8 \pm 1.2$ & $4.3 \pm 1.3$ & $4.4 \pm 0.9$ \\
\hline (E)-2-heptenal & $9.0 \pm 1.5$ & $9.5 \pm 0.2$ & $8.0 \pm 1.8$ & $9.6 \pm 2.2$ & $1.0 \pm 0.3$ & $2.5 \pm 0.4$ \\
\hline 1-octen-3-ol & $2.4 \pm 0.6$ & $3.3 \pm 0.7$ & $5.5 \pm 0.4$ & $6.2 \pm 1.7$ & $2.3 \pm 0.6$ & $3.5 \pm 0.7$ \\
\hline octanal & $2.0 \pm 0.3$ & $2.6 \pm 0.4$ & $3.3 \pm 0.5$ & $2.5 \pm 0.6$ & nd & nd \\
\hline sum of $(E, Z)$ - and $(E, E)-2,4$-heptadienal & $6.4 \pm 1.3$ & $10.2 \pm 2.4$ & $14.4 \pm 2.1$ & $25.0 \pm 2.2$ & $1.7 \pm 0.4$ & $1.8 \pm 0.4$ \\
\hline (E)-2-octenal & $4.7 \pm 1.3$ & $8.7 \pm 2.2$ & $6.0 \pm 1.5$ & $6.7 \pm 1.4$ & $1.2 \pm 0.5$ & $2.2 \pm 0.5$ \\
\hline nonanal & $3.9 \pm 0.5$ & $3.9 \pm 0.6$ & $7.5 \pm 0.8$ & $5.6 \pm 1.1$ & $3.7 \pm 0.8$ & $3.0 \pm 0.4$ \\
\hline$(E, E)-3,5$-octadien-2-one & $1.1 \pm 0.3$ & $1.7 \pm 0.4$ & $1.1 \pm 0.5$ & $1.8 \pm 0.4$ & $0.5 \pm 0.1$ & $1.4 \pm 0.3$ \\
\hline octanoic acid & $0.8 \pm 0.1$ & $1.1 \pm 0.0$ & $1.3 \pm 0.1$ & $1.5 \pm 0.2$ & $0.4 \pm 0.1$ & $0.8 \pm 0.1$ \\
\hline
\end{tabular}

* Faba bean extracts were prepared from the Kontu cultivar from two harvesting years $(2015,2016)$. (3 replicate measurements; nd: not detected.)

represent neutral and mildly alkaline conditions, respectively. At $\mathrm{pH}$ 5.0, mainly the faba bean LOX was expected to have activity. At $\mathrm{pH} 8$, the faba bean lipase was expected to show activity. And at $\mathrm{pH} 6.4$, the LOX was close to its optimum $\mathrm{pH}$, and the lipase might potentially have shown some activity. In the incubations with faba bean extracts, only the endogenous lipids of faba bean were present and subjected to enzymatic reactions. In the $3 \%$ and $5 \%$ rapeseed oil emulsions, mainly the lipids of the rapeseed oil were expected to react. In the case of the rapeseed oil fatty acids, no reaction catalysed by lipase was needed, and the FFAs were available at once to LOX-catalysed oxidation.

In the faba bean extracts, only the endogenous lipids (1.4\%) of faba bean that had 54\% linoleic acid and 5\% $\alpha$-linolenic acid were subjected to oxidation (Lizarazo et al., 2015). In these extracts, hexanal was the major volatile lipid oxidation product, followed by 2-pentylfuran, 1hexanol and 1-octen-3-ol (Table 2). The volatile profiles differed markedly at different pHs. At $\mathrm{pH} 5.0$, the proportion of hexanal was about $75 \%$, whereas at $\mathrm{pH} 6.4$, it was $<40 \%$. In addition, at $\mathrm{pH} 6.4$, the amounts of other products increased and the amount of hexanal decreased, indicating that apparently higher LOX activity enhanced lipid oxidation and that higher activity of the hydroperoxide-decomposing enzymes enhanced formation of other products, including 1-hexanol and 2-pentylfuran. At the highest $\mathrm{pH} 8$, much less lipid oxidation occurred than at the other pHs, and it yielded only low levels of volatile compounds, which is in line with the low LOX activity at this $\mathrm{pH}$. The incubation $\mathrm{pH}$ had similar effects on the profiles of the volatile lipid oxidation products of the faba bean samples from both the cultivation years.

When rapeseed oil was added as a substrate in faba bean emulsions, the contents of the volatile lipid oxidation products increased remarkably, especially at pH 6.4 (Table 2), at which the relevant lipiddegrading enzymes are considered active. At $\mathrm{pH} 6.4$, the addition of $3 \%$ of oil increased the sum of the products by 2 -fold, and the addition of $5 \%$ by 3 -fold. At other pHs, the amounts of products remained relatively stable. It was interesting to note that when the proportion of rapeseed oil in the emulsions at pH 6.4 increased from 3\% to 5\%, the amounts of selected volatile compounds, including hexanal and 2,4heptadienal, increased markedly, but the amounts of other volatile compounds increased less or not at all. In general, there were no major differences between the profiles of the volatile lipid oxidation products from the faba bean samples from the two cultivation years.

Rapeseed oil also had an effect on the compounds formed, because two characteristic $\alpha$-linolenic acid products, 2,4-heptadienal and (E)-2pentenal, could be measured only in the emulsions. The proportion of hexanal decreased, giving greater roles to other compounds, particularly at pH 6.4. However, in the emulsions, the amounts of 2-pentylfuran and 1-octen-3-ol were similar to or even less than in the extracts, indicating that they were not produced from rapeseed oil. At the lower $\mathrm{pH}$ of 5.0, the effect of rapeseed oil addition was much less or even entirely absent, and at $\mathrm{pH} 8$, the addition of rapeseed oil did not affect the amounts or the profile of lipid oxidation products.

When emulsions were prepared with fatty acids saponified from rapeseed oil (Table 3), the formation of volatile compounds was remarkably greater than in emulsions prepared with rapeseed oil, which clearly shows that FFAs are superior to TAGs as substrates of faba bean LOX. At pH 5.0, the sums of the volatile compounds in the emulsions that had fatty acids were from 4 to 8 -fold compared to the emulsions with rapeseed oil. At $\mathrm{pH} 6.4$, they were from 2 to 3-fold, and at $\mathrm{pH} 8.0$, they were from 6 to 15 -fold. This means that the reaction rates with FFAs were enhanced the most in comparison to TAGs at pH 8.0, which could partly be explained by the very low amounts of volatile compounds formed with the respective rapeseed oil samples. In addition, it may be that rapeseed oil FFAs had autoxidised more extensively during 
the preparation of emulsions than rapeseed oil, because FFAs are known to autoxidise faster than TAGs (Schaich et al., 2013). This would increase the level of volatile lipid oxidation products in all rapeseed oil FFA samples. The amounts of volatile compounds were the highest at $\mathrm{pH}$ 6.4, followed by the amounts in rapeseed oil fatty acid emulsions at $\mathrm{pH}$ 5.0, at which the faba bean LOX is able to begin the LOX pathway. The relatively high amounts of volatile compounds at $\mathrm{pH} 8.0$ could not be fully explained, because faba bean LOX was shown to possess higher activity at lower $\mathrm{pH}$. It cannot be ruled out that faba bean has other LOX isoenzymes that could have their optima at higher $\mathrm{pH}$. Again, the faba bean materials from both cultivation years produced comparable amounts and profiles of volatile lipid oxidation products.

There were apparent differences between the lipid oxidation product profiles of rapeseed oil and rapeseed oil fatty acid emulsions. With rapeseed oil, hexanal contributed to between $34 \%$ and $69 \%$ of the peak areas of the volatile lipid oxidation products, whereas with FFAs, it contributed to only between $19 \%$ and $32 \%$. Thus, with more extended oxidation, further reaction products began to become more apparent compared to hexanal.

Octanoic acid was detected in all rapeseed oil fatty acid emulsions and the rapeseed oil emulsions at $\mathrm{pH}$ 6.4. This is a typical reaction product of 9-hydroperoxide from linoleic acid and can be formed easily from fatty acids but not from esters. In addition, $(E, E)$-3,5-octadien-2one could also be measured in emulsions that had fatty acids but not in those that had oil. The $(E, E)$-3,5-octadien-2-one is an important volatile in terms of off-flavour, because in combination with heptanal, it has been related to a fishy malodour, which is typical of materials with $n-3$ polyunsaturated fatty acids (Marsili \& Laskonis, 2014).

The importance of $\mathrm{pH}$ in further reaction routes after the scission of hydroperoxides was also apparent in the amounts of 2-pentylfuran in the emulsions that had rapeseed oil fatty acids. Although the amounts of 2-pentylfuran at pHs 6.4 and 8.0 were similar, the total amounts of products at $\mathrm{pH} 6.4$ were about 3 -fold compared to that at $\mathrm{pH}$ 8.0. Thus, formation of 2-pentylfuran was enhanced under alkaline conditions, and with its flavour characterised as like green beans (Belitz et al., 2004), 2-pentylfuran could modify the flavour of the emulsion at $\mathrm{pH} 8.0$ from that at lower $\mathrm{pHs}$. It has been shown that $\mathrm{pH}$ has a strong effect on the off-flavours of faba bean protein isolates (Schultz, Hoppe, \& Schmandke, 1988). The authors indicated a fruity off-flavour in products that had acidic pHs and a pleasant, pea-like, flavour at neutral pHs.

Interestingly, the profiles of volatile compounds in emulsions having fatty acids included five compounds, hexanal, 1-hexenol, 1octen-3-ol, (E)-2-hexenal and 2,4-heptadienal, which in one study were considered to contribute to the beany flavour in cooked soymilk when analysed by dynamic headspace dilution analysis and GC-olfactometry-MS (Lv, Song, Li, Wu, \& Guo, 2011). Another study used (E,E)-2,4-nonadienal, (E,E)-2,4-decadienal, 3-methyl-1-butanol and 2-pentylfuran to quantify the formation of beany flavour in legume flours over the course of germination (Xu, Jin, Lan, Rao, \& Chen, 2019). Of these, 2-pentylfuran was a major product found in all incubated faba bean emulsions, whereas (E,E)-2,4-nonadienal and 2,4-decadienal were measured only in faba bean extracts incubated with linoleic acid.

Finally, it should be pointed out that most of the volatile compounds identified in this study could be found in Canadian-grown faba beans (Akkad, Kharraz, Han, House, \& Curtis, 2019; Oomah et al., 2014), indicating that the products included in this study are typical for faba beans. Hexanal, $(E)$-2-octenal, nonanal and (E)-2-heptenal were also measured as being the major volatile lipid oxidation products in emulsions having faba bean extracts and rapeseed oil after seven days of storage (Gúrbứz et al., 2018).

In conclusion, both lipase and LOX activities are present in faba bean, and both may cause off-flavour problems during food processing. The risk is obvious, at least under neutral conditions, when both enzymes show activity. The potential of LOX as the first enzyme of the LOX pathway to produce volatile lipid oxidation products is apparent.
This study showed that adding oil, especially FFAs, to faba bean extracts while preparing the emulsions enhances formation of volatile lipid oxidation products. In addition, $\mathrm{pH}$ affected the further reactions of the LOX pathway and thereby the profiles of the volatile lipid oxidation products. The role of lipase in food preparation models remains somewhat unclear. Unfortunately, based on the amounts of volatile lipid oxidation products formed in the rapeseed oil emulsions at $\mathrm{pH} 8.0$, it was not possible to conclude if faba bean lipase catalysed hydrolysis of TAGs to FFAs. In addition, it would be interesting to explore how stable and active faba bean lipase remains under long-term storage conditions, which would enable evaluation of whether lipase causes offflavour problems in faba bean flours comparable to those known to occur in poorly heat-treated oat flours. Nevertheless, inactivation of faba bean enzymes is crucial in producing appealing foods from faba bean.

\section{CRediT authorship contribution statement}

Anna-Maija Lampi: Supervision, Writing - original draft, Writing review \& editing. Zhen Yang: Supervision, Writing - original draft, Writing - review \& editing. Otto Mustonen: Supervision, Writing original draft, Writing - review \& editing. Vieno Piironen: Supervision, Writing - original draft, Writing - review \& editing.

\section{Declaration of Competing Interest}

The authors declare that they have no known competing financial interests or personal relationships that could have appeared to influence the work reported in this paper

\section{Acknowledgements}

The authors would like to thank Miikka Olin for his kindly technical assistances, and Frederick Stoddard for providing the faba bean samples of the cultivars. We would also thank CSC and Finnish Cultural Foundation for funding the Ph.D studies of Z. Yang.

\section{Appendix A. Supplementary data}

Supplementary data to this article can be found online at https:// doi.org/10.1016/j.foodchem.2019.125982.

\section{References}

Akkad, R., Kharraz, E., Han, J., House, J. D., \& Curtis, J. M. (2019). Characterisation of the volatile flavour compounds in low and high tannin faba beans (Vicia faba var. minor) grown in Alberta, Canada. Food Research International, 120, 285-294.

Al-Obaidy, H. M., \& Siddiqi, A. M. (1981). Properties of broad bean lipoxygenase. Journal of Food Science, 46, 622-625.

Baysal, T., \& Demirdöven, A. (2007). Lipoxygenase in fruits and vegetables: A review. Enzyme and Microbial Technology, 40, 491-496.

Belitz, H.-D., Grosch, W., \& Schieberle, P. (2004). Food Chemistry. (3rd revised ed.) Berlin: Spinger, (Chapter 3)

Bleé, E. (1998). Phytooxylipins and plant defence reactions. Progress in Lipid Research, 37, 33-72.

Boukid, F., Zannini, E., Carini, E., \& Vittadini, E. (2019). Pulses for bread fortification: A necessity or a choice? Trends in Food Science \& Technology, 88, 416-428.

Calles, T., del Castello, R., Baratelli, M., Xipsiti, M., \& Navarro, D. K. (2019). The International Year of Pulses - Final report. FAO, 40 pp. Licence: CC BY-NC-SA 3.0 IGO.

Chang, P. R. Q., \& McCurdy, A. R. (1985). Lipoxygenase activity in fourteen legumes. Canadian Institute of Food Science and Technology, 18, 94-96.

Clemente, A., Olías, R., \& Olías, J. M. (2000). Purification and characterization of broad bean lipoxygenase isoenzymes. Journal of Agricultural and Food Chemistry, 48, 1070-1075.

Day, L. (2013). Proteins form land plants - Potential resources for human nutrition and food security. Trends in Food Science \& Technology, 32, 25-42.

Dundas, D. G. A., Henderson, H. M., \& Eskin, N. A. M. (1978). Lipase from Vicia faba minor. Food Chemistry, 3, 171-178.

Gardner, H. W. (2003). Lipoxygenase and associated enzymes. In J. R. Whitaker, A. G. J. Voragen, \& D. W. S. Wong (Eds.). Handbook of Food Enzymology (pp. 557-567). New York: Marcel Dekker Inc. 
Gilham, D., \& Lehner, R. (2005). Techniques to measure lipase and esterase activity in vitro. Methods, 36, 139-147.

Gû́rbûz, G., Liu, C., Jiang, Z., Pulkkinen, M., Piironen, V., Sontag-Strohm, T., \& Heinonen, M. (2018). Protein-lipid co-oxidation in emulsions stabilized by microwave-treated and conventional thermal-treated faba bean proteins. Food Science and Nutrition, 6 , 1032-1039.

Henderson, H. M., Shambrock, D. L., \& Eskin, N. A. M. (1981). The enzymatic deacylation of p-nitrophenyl esters and phosphatidylcholine in vicia faba minor. Food Chemistry, 7, 249-256.

Hinchcliffe, C., McDaniel, M., Vaisey, M., \& Eskin, N. A. M. (1977). The flavor of fababeans as affected by heat and storage. Canadian Institute of Food Science and Technology, 3, 181-184.

Jeleń, H., \& Wąsowicz, E. (2012). Lipid-derived flavour compounds. In H. Jeleń (Ed.). Food Flavors: Chemical, Sensory and Technological Properties (pp. 65-93). Boca Raton: CRC Press.

Jiang, Z. Q., Pulkkinen, M., Wang, Y. J., Lampi, A.-M., Stoddard, F. L., Salovaara, H., ... Sontag-Strohm, T. (2016). Faba bean flavour and technological property improvement by thermal pre-treatments. LWT - Food Science and Technology, 68, 295-305.

Lv, Y.-C., Song, H.-L., Li, X., Wu, L., \& Guo, S.-T. (2011). Influence of blanching and grinding process with hot water on beany and non-beany flavor in soymilk. Journal of Food Science, 76, 520-525.

Lizarazo, C. L., Lampi, A.-M., Liu, J., Sontag-Strohm, T., Piironen, V., \& Stoddard, F. L. (2015). Nutritive quality and protein production from grain legumes in a boreal climate. Journal of the Science of Food and Agriculture, 95, 2053-2064.

Marsili, R., \& Laskonis, C. (2014). The importance of odourant synergy effects in understanding malodour problems in DHA and EPA products. Lipid Technology, 26, $31-34$.

Mosblech, A., Feussner, I., \& Heilmann, I. (2009). Oxylipins: Structurally diverse metabolites from fatty acid oxidation. Plant Physiology and Biochemistry, 47, 511-517.

Oomah, B. D., Razafindrainibe, M., \& Drover, J. C. (2014). Headspace volatile components of Canadian grown low-tannin faba bean (Vicia faba L.) genotypes. Journal of the Science of Food and Agriculture, 94, 473-481.

Paradiso, V. M., Summo, C., Pasqualone, A., \& Caponio, F. (2009). Evaluation of different natural antioxidants as affecting volatile lipid oxidation products related to off-flavours in corn flakes. Food Chemistry, 113, 543-549.

Roland, W. S. U., Pouvreau, L., Curran, J., van de Valde, F., \& de Kok, P. M. T. (2017). Flavor aspects of pulse ingredients. Cereal Chemistry, 94, 58-65.

Sanz, C., \& Pérez, A. G. (2010). Plant metabolic pathways and flavor biosynthesis. In Y. H. Hui (Ed.). Handbook of Fruit and Vegetable Flavors (pp. 129-155). New York: John Wiley \& Sons Inc.

Schaich, K. M., Shahidi, F., Zhong, Y., \& Eskin, N. A. M. (2013). Lipid oxidation. In N. A. M. Eskin, \& F. Shahidi (Eds.). Biochemistry of Foods (pp. 419-478). ((3rd ed.)(pp.). London: Elsevier Inc.

Schultz, M., Hoppe, K., \& Schmandke, H. (1988). Off-flavour reduction in Vicia Faba bean protein isolate. Food Chemistry, 30, 129-135.

Sparvoli, F., Bollini, R., \& Cominelli, E. (2015). Nutritional value. In A. M. De Ron (Ed.) Grain Legumes (pp. 291-325). New York: Springer.

Springmann, M., Clark, M., Mason-D-Croz, D., Wiebe, K., Bodirsky, B. L., Lassaletta, L., ... Willett, W. (2018). Options for keeping the food system within environmental limits. Nature, 562, 519-525.

Yang, Z., Piironen, V., \& Lampi, A.-M. (2017). Lipid-modifying enzymes in oat and fababean. Food Research International, 100, 335-343.

Yang, Z., Piironen, V., \& Lampi, A.-M. (2019). Epoxy and hydroxy fatty acids as nonvolatile lipid oxidation products in oat. Food Chemistry, 295, 82-93.

Xu, M., Jin, Z., Lan, Y., Rao, J., \& Chen, B. (2019). HS-SPME-GC-MS/olfactometry combined with chemometrics to assess the impact of germination on flavor attributes of chickpea, lentil, and yellow pea flours. Food Chemistry, 180, 83-95.

Zhu, D., \& Damodaran, S. (2018). Removal of off-flavour-causing precursors in soy protein by concurrenttreatment with phospholipase $\mathrm{A}_{2}$ and cyclodextrins. Food Chemistry, 264, 319-325. 